\section{PHANTOM RAILINGS}

\section{LONDRES, INGLATERRA}

\section{CATALINA POLLAK}

\section{2-2014}

CATALINA POLLAK | VISITING COLLABORATION ASSOCIATE, UNIVERSITY OF LONDON, LONDRES, INGLATERRA.

Arquitecta, Pontificia Universidad Católica de Chile, 2001; Magíster en Artes Visuales, Universidad de Chile, 2006-2007; Master in Architecture, Architectural Association, 2010. Actualmente vive en Londres donde dirige Public Interventions, plataforma interdisciplinaria para la investigación y desarrollo de proyectos para la reactivación de espacio público. Además se desempeña como investigadora invitada en The University of London. En el cruce entre estudios urbanos, geografía, políticas públicas, historia y teoría crítica, pero operando desde las artes visuales y el uso de nuevos medios, su trabajo cuestiona temas de accesibilidad y democracia urbana a través de procesos que invitan a la participación y que resaltan el valor de lo público.

Phantom Railings es una instalación acústica interactiva que utiliza el movimiento de los peatones para evocar el fantasma de una reja inexistente. Instalada en el barrio londinense de Bloomsbury, específicamente en Malet Street Gardens - un jardín de uso colectivo cuyas rejas fueron cortadas durante la Segunda Guerra Mundial como parte de la propaganda política de guerra- el proyecto busca hacer evidente la ausencia del cierro perimetral del jardín al recrear el familiar sonido que producen las rejas metálicas cuando son recorridas con un palo.

Londres, al contrario de otras ciudades europeas, es una ciudad que no ha sido pensada a partir del espacio público. La plaza privada, un jardín común de uso exclusivo para las casas alrededor, aparece como la tipología dominante en la forma en que se desarrolla la ciudad durante la época victoriana. Una estructura espacial que perpetúa la rígida estructura social del momento.

Las rejas de fierro fundido, elemento recurrente en el paisaje urbano de la cuidad, vienen a formalizar ese límite entre la plaza y la calle en un ambiguo juego entre permeabilidad visual y exclusión física. La reja hace posible la coexistencia y diferenciación de distintos ordenes sociales en la demarcación de un adentro y un afuera que recíprocamente sostienen la mirada.

Si bien la decisión política de cortar las rejas durante la guerra tenía como objetivo acumular metal para la fabricación de municiones, su retiro no fue simplemente el resultado de una decisión pragmática. La iniciativa vino a representar un acto simbólico para una sociedad que buscaba más igualdad y que quería espacios que representaran ese cambio.

Con el retiro de las rejas vino la promesa de la ciudad democrática: la exposición de la plaza privada sin su cierro perimetral generó repentinamente acceso a espacios verdes en el centro de la ciudad. Un episodio que en muchos casos significó la consolidación de un espacio público antes inexistente. Sin embargo, la democratización del suelo urbano no significó que la plaza pública preservara su democrática apertura. En Bloomsbury, en particular, todas las plazas que pasaron a ser de uso público, tarde o temprano recuperaron sus rejas perimetrales como parte de un programa de restauración histórica financiado por la National Heritage Lotery Fund - HLF. Y junto con la reja se impone el horario de cierre, una restricción común para plazas y parques cercados que opera hasta hoy.

Las rejas constituyen una parte importante del aparato de seguridad en Londres. Detrás de su ornamental apariencia se esconde la austera función de controlar el uso del espacio público. Líneas de defensa creadas para proteger el privilegio de unos pocos, hoy nos aseguran un espacio urbano sanitizado al costo de ser excluidos.
Hace 70 años una guerra y una discusión sobre la democratización de los espacios colectivos se conjugaron en el retiro de los cierros de fierro fundido de una serie de jardines urbanos en Londres. Este proyecto trae de vuelta esa reflexión y verifica su vigencia a través del sonido y el movimiento.

PALABRAS CLAVE: URBANISMO INGLATERRA, INSTALACIÓN, ESPACIO PÚBLICO, MEMORIA.

\section{BibLIOGRAFía}

Agoraphobia [en línea]. Londres, Centre for Creative Collaboration - University of London, 2013. Disponible en <http://publicinterventions.org/projects/AGORAPHOBIA/>

PHANTOM RAILINGS / Arquitecta: Catalina Pollak / Ubicación: Malet Street Gardens, Bloomsbury, Londres, Inglaterra / Patrocinador: Centre for Creative Collaboration C4CC, University of London / Montaje: Bartira Sena, Deborah Davis / Programación: Ken Boak, Daniel Soltis / Asesoría en ingeniería eléctrica: Adrian Godwin, Steve Kelly / Asesoría en ingeniería acústica: Guillaume Senzes / Documentación histórica: Nathanael Price / Presupuesto: sin datos / Año de proyecto: 2012 / Año de instalación: 2012-2014 / Fotografía: Rosario Montero, Catalina Pollak / Postproducción fotográfica: Sachiyo Nishimura.

Malet Street Gardens es el único jardín en Bloomsbury donde las rejas no fueron recuperadas; en parte, porque se trata de un jardín hundido donde los límites están claramente definidos por el suelo. Salvo por el portón de acceso, único tramo de la reja que no fue cortado durante la guerra, el resto del muro perimetral aún muestra el vestigio de los anclajes metálicos de la reja original. La particularidad de este jardín es que ofrece la posibilidad de revisitar un episodio histórico desde una evidencia material que, además, hace posible la articulación de una narrativa crítica: ¿existe un mejor lugar para hacer visibles las rejas que cuando están completamente ausentes?

Phantom Railings nace como una provocación a la abundancia y monumental invisibilidad que tienen las rejas en Londres. Una operación que busca traer a discusión pública la reja como aparato biopolítico de control en la vigilancia del espacio público. Entonces, la estrategia consistió en hacer visibles las rejas tanto física como políticamente desde la apropiación de un pasado histórico que habla del mismo proceso de democratización que las vio partir.

El traqueteo de niños corriendo palo en mano a lo largo de rejas metálicas, se convierte en la imagen conducente del proyecto. La evocación de un pasado nostálgico que también sugiere otros gestos de protesta. Cualquiera sea la referencia inmediata, el sonido producido por el objeto material que ya no está ahí implica crear, de algún modo, su fantasma: el sonido de los Phantom Railings siguiendo a los peatones como si ellos mismos estuvieran tocando (o protestando contra) la reja inexistente.

60 unidades acústicas, una por cada vestigio existente de los montantes removidos, se instalan dentro de once cajas metálicas negras cubriendo 50 m lineales del muro noreste del jardín. Cada unidad acústica está equipada con un sensor infrarrojo conectado a un microprocesador y a un parlante de $8 \mathrm{~W}$ que reproduce uno de los veinticuatro archivos de sonido disponibles. Como un instrumento a escala urbana, el sonido de cada poste metálico varía su tono y timbre de acuerdo a la distancia y velocidad detectada. La reproducción de esa partitura -o la representación gráfica de la coreografía de los peatones frente a la instalación-fue posible mediante la recolección de la información a través de transmisores de radiofrecuencia y su posterior visualización transmitida online en tiempo real (fig. 18).

Phantom Railings toma lo que es inherente a la calle y lo transforma en sonido. Velocidad y proximidad son los dos parámetros que hacen de cada trayectoria una experiencia individual y única. Una dinámica que permite desplazar la tensión del objeto a la agencia del sujeto y, de esta manera, transformar la experiencia estética en apropiación creativa. ARQ www.publicinterventions.org 


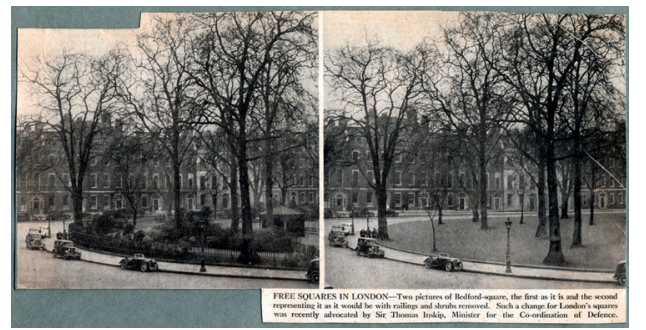

Recorte de prensa, Archivo Histórico Daily Telegraph, abril de 1937. En la nota se lee: “PLAZAS LIBRES EN LONDRES - Dos imágenes de Bedford Square, la primera como es y la segunda representado como sería sin rejas y arbustos. Tal cambio en las plazas de Londres fue recientemente promovido por Sir Thomas Inskip, Ministro para la Coordinación de la Defensa". Fuente: Archivo Histórico Holborn Library, Londres.

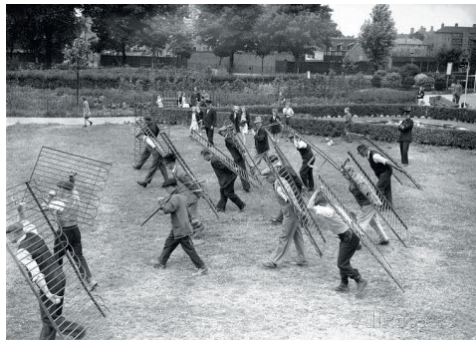

Registro histórico del retiro de rejas en Londres. Fuente: $\sin$ datos.
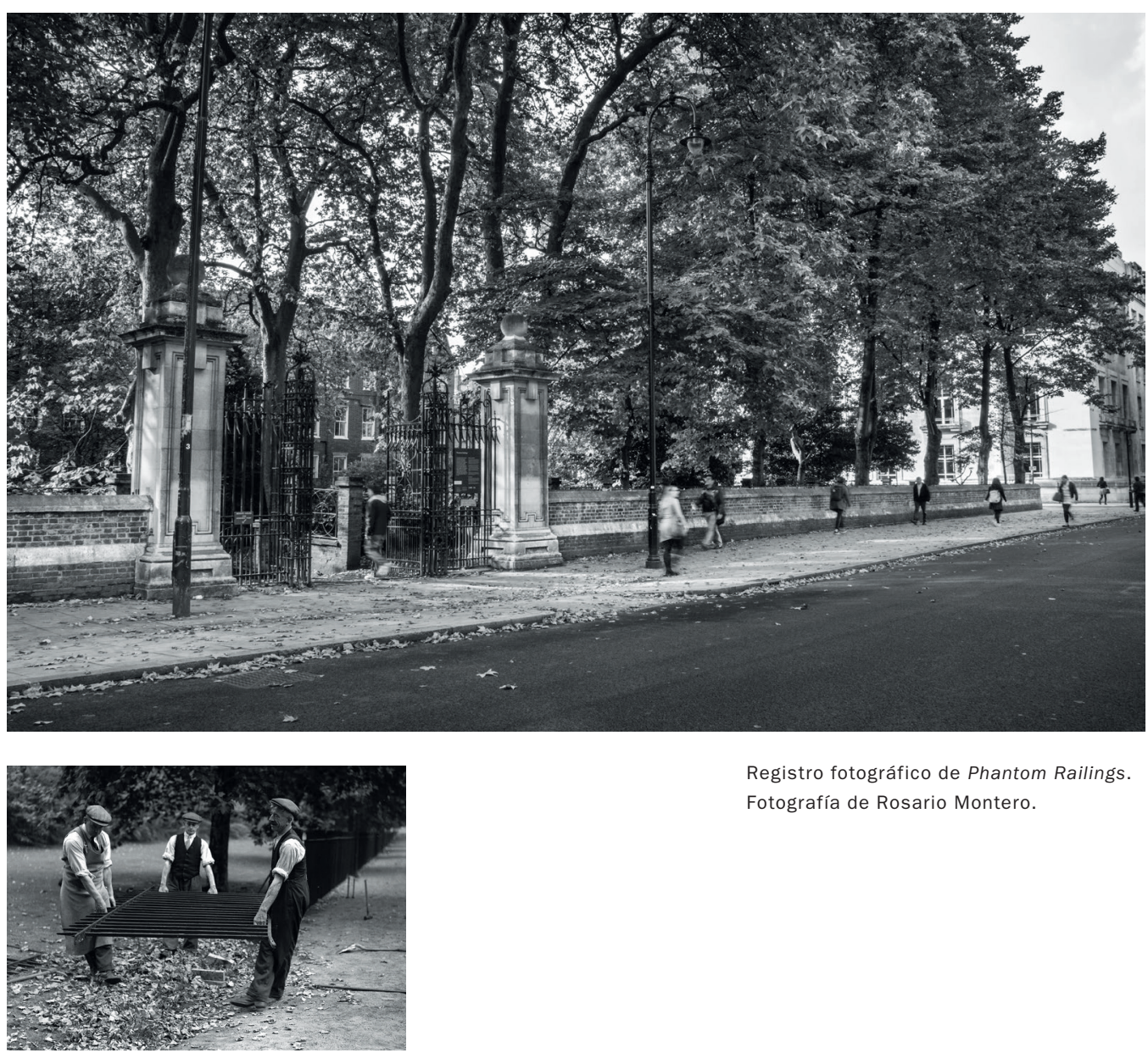

Fotografía de Rosario Montero.

Registro histórico del retiro de rejas en

Londres. The Mall, 1941. Fuente: sin datos.

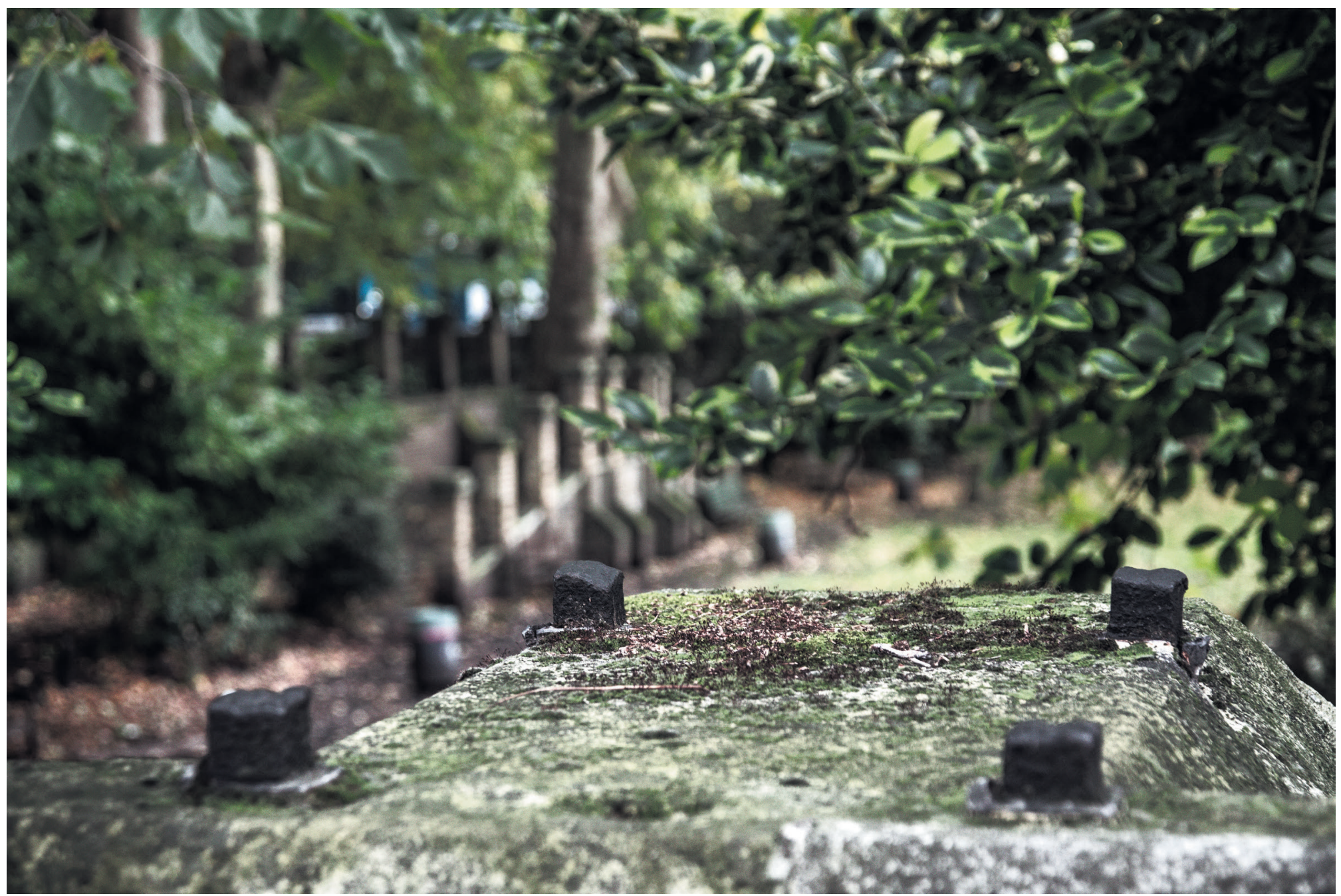

Malet Street Gardens, 2014. Vestigio de los montantes

metálicos de la reja original. Fotografía de la autora. 

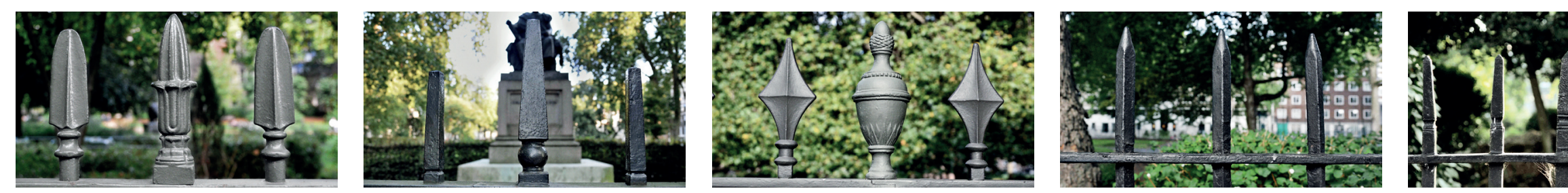

Brunswick Square (publica), Tavistock

Square (pública), Bedford Square (privada), Queen Square (pública), Cartwright Gardens

(privada), Brunswick Square (pública), Woburn Square (pública). Fotografías de la autora.

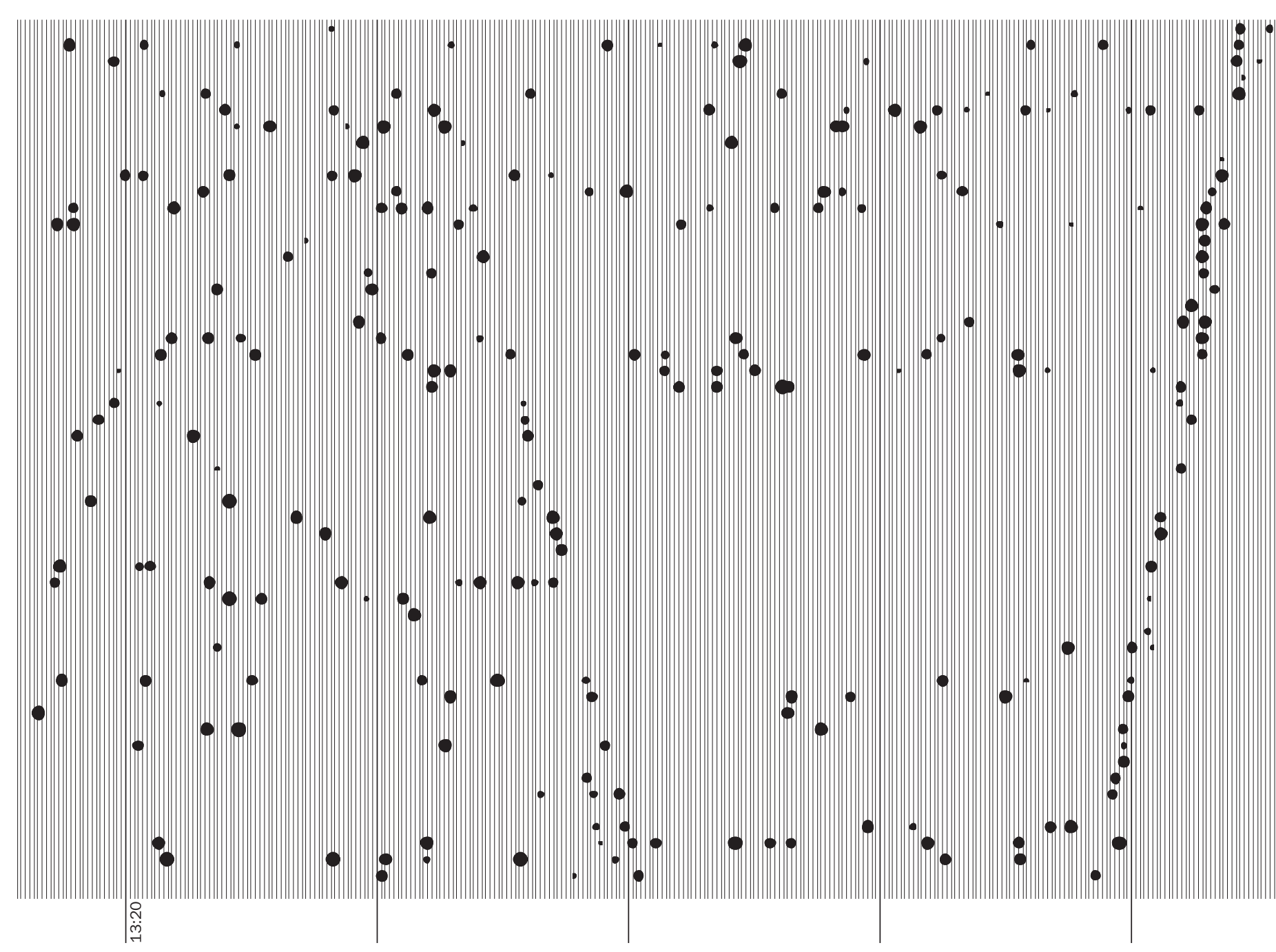

?.

?.

:.

i l.
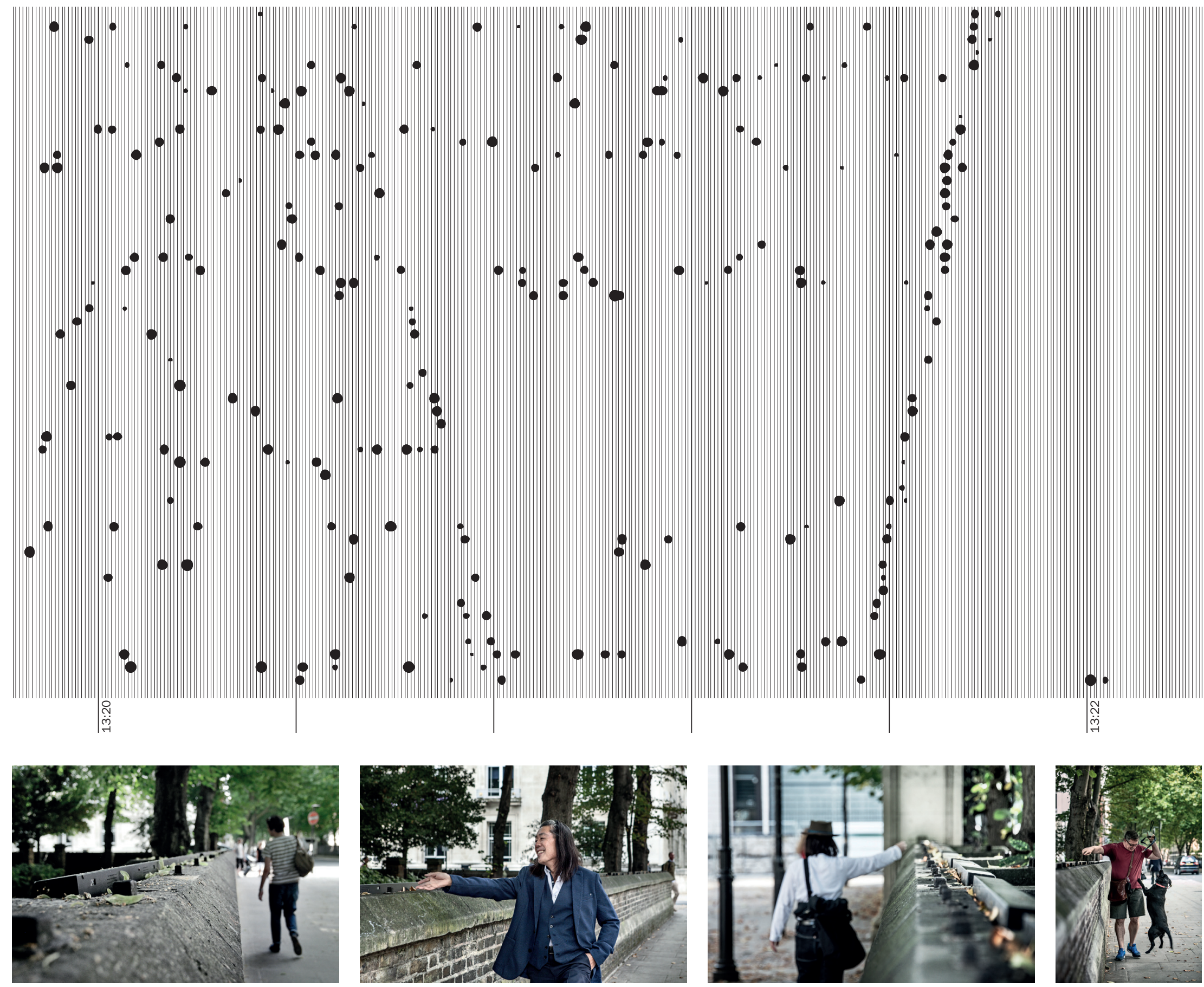

Fotografía de la autora.

Fotografías de Rosario Montero. 

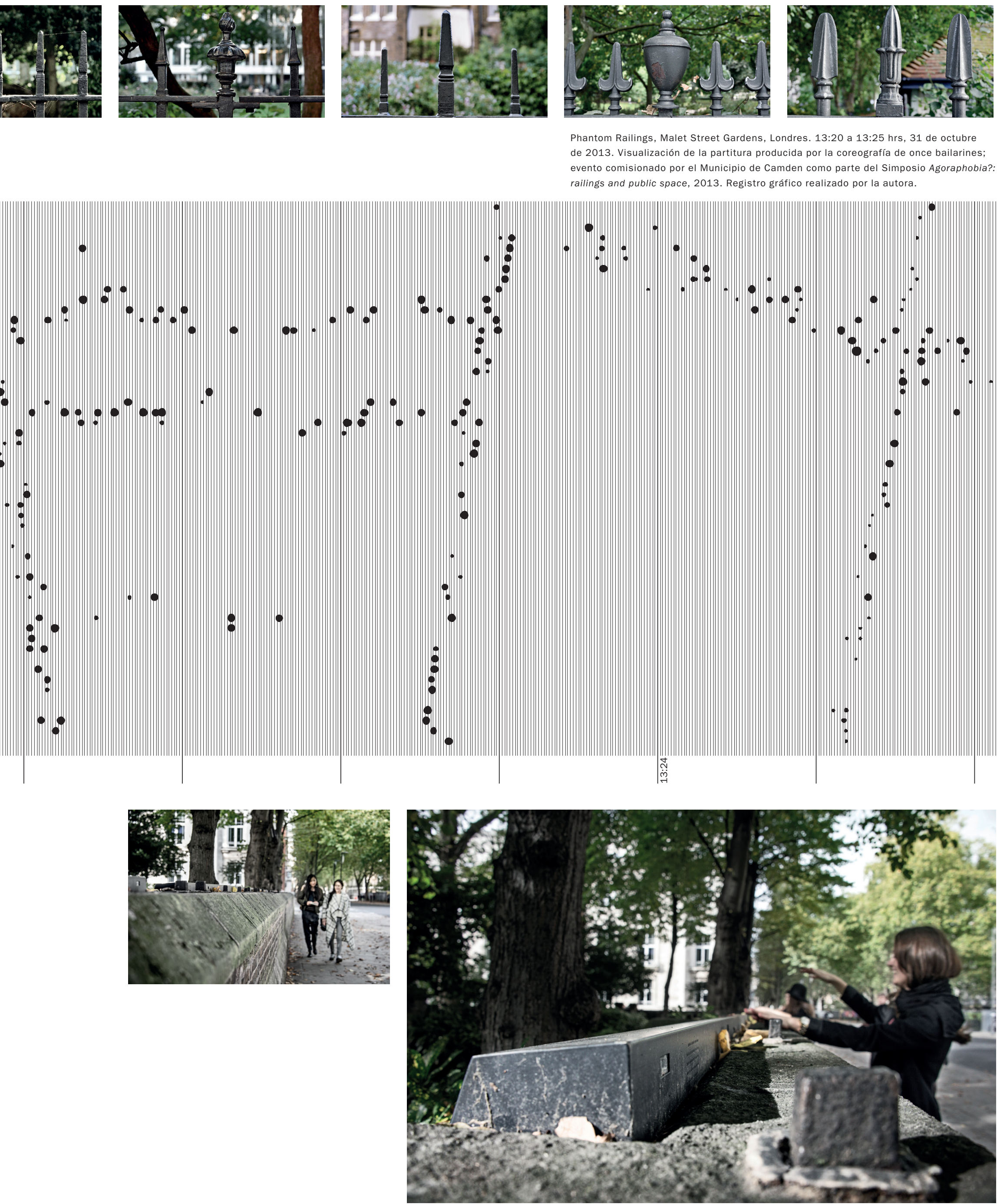